\title{
Spontaneous acute hemorrhage within a subependymoma of the lateral ventricle: successful emergent surgical removal through a frontal transcortical approach
}

\author{
R. Carrasco; J.M. Pascual*; M. Navas*; J. Fraga**; R. Manzanares-Soler*** and R.G. Sola*
}

Department of Neurosurgery. Ramón y Cajal University Hospital. Departments of Neurosurgery*, Neuropathology** and Neuroradiology***. La Princesa University Hospital. Madrid, Spain.

Summary

Introduction. Subependymomas are benign neoplasms intimately related to the ventricular system which only exceptionally associate hemorrhagic events. We present neuroradiological and pathological evidences of intratumoral hemorrhage within a single case of subependymoma operated on at our institution. Additionally we analyze retrospectively the well-defined reports of similar cases published in the scientific literature.

Case report. A 71-year-old man on anticoagulant therapy presented with abrupt and progressive deterioration of his level of consciousness. Emergent computed tomography and magnetic resonance imaging evidenced signs of acute bleeding within a mass located at the frontal horn of the left lateral ventricle, producing obstructive biventricular hydrocephalus. The lesion was immediately and completely removed through a left frontal transcortical approach. Pathological diagnosis was consistent with subependymoma displaying areas of microhemorrhage. After surgery the patient developed global anterograde and retrograde amnesia.

Conclusions. A spontaneous hemorrhagic event within an asymptomatic lateral ventricle subependymoma can result in a surgical emergence as a consequence of sudden obstruction of cerebrospinal fluid pathways. Prompt and radical surgical removal of the mass, which allows a rapid resolution of hydrocephalus and prevents the risk of rebleeding, may constitute the safest management strategy.

KEY WORDS: Basal forebrain. Brain tumor hemorrhage. Lateral ventricle. Septal region. Subependymoma.

Subependimoma de ventrículo lateral con hemorragia intratumoral aguda espontánea: resección quirúrgica urgente mediante un abordaje frontal transcortical.

Recibido: 10-02-10. Aceptado: 30-08-10
Resumen

Introducción. Los subependimomas son neoplasias benignas que se desarrollan en estrecha relación con el sistema ventricular y que excepcionalmente asocian fenómenos hemorrágicos. Describimos el caso de un subependimoma localizado en el ventrículo lateral que presentó una hemorragia intratumoral aguda de forma espontánea, como se evidenció en los estudios neurorradiológicos y patológicos realizados, incluyendo un análisis exhaustivo de los casos similares descritos en la literatura científica.

Caso clínico. Se trata de un varón de 71 años que recibía tratamiento anticoagulante, y que presentó un cuadro brusco y progresivo de disminución del nivel de conciencia. Los estudios de neuroimagen evidenciaron la presencia de una masa localizada en el ventrículo lateral izquierdo, con signos de hemorragia reciente en su seno, que producía hidrocefalia biventricular aguda. La lesión fue resecada en su totalidad de forma urgente mediante un abordaje frontal transcortical. El estudio patológico de la lesión demostró que se trataba de un subependimoma con focos hemorrágicos. En el periodo postoperatorio, el paciente presentó un déficit de memoria global, tanto anterógrada como retrógrada.

Conclusiones. Los episodios de hemorragia espontánea aguda constituyen un fenómeno excepcional en el caso de los tumores de histología benigna como los subependimomas, y pueden transformar un curso clínico asintomático en una emergencia quirúrgica debido al desarrollo de hidrocefalia aguda. La extirpación completa de la lesión de forma urgente representa la opción de manejo quirúrgico más apropiada, ya que permite un reestablecimiento inmediato de la circulación de líquido cefalorraquídeo y previene la aparición de resangrado.

PALABRAS CLAVE: Prosencéfalo basal. Región septal. Subependimoma. Tumor cerebral hemorrágico. Ventrículo lateral.

Introduction

Subependymomas are low-frequency tumors that 
appear near the ventricular system and spinal cord. They are characterized by a benign clinical course, the rate of symptomatic subependymoma being estimated in a $40 \%$ approximately ${ }^{8,11}$. Only exceptionally does this kind of tumor present an aggressive behaviour ${ }^{13}$. Spontaneous hemorrhage associated with these lesions represents an exceedingly rare event that may cause a rapid and severe neurological derangement in the patient. In this report, we present a single case of subependymoma displaying a spontaneous acute intratumoral hemorrhage, which was surgically removed on an emergency basis at our institution. We have performed a systematic review of clinical series and well-described single reports of subependymomas, analyzing the features and outcome of those cases associating tumoral bleeding.

\section{Case report}

A 71 year-old man was brought to the emergency department of a primary hospital by his relatives, after suffering an abrupt-onset episode of disorientation, incoherent speech and memory deficit. He suffered from arterial hypertension and chronic atrial fibrillation, so he was being treated with acenocumarol. An emergent brain computed tomography (CT) was obtained, demonstrating a solid mass near the left foramen of Monro, with signs of both intratumoral and intraventricular acute hemorrhage. There were also signs of active biventricular obstructive hydrocephalus (fig 1).

During the transfer to our neurosurgical department, the patient presented a progressive deterioration of his

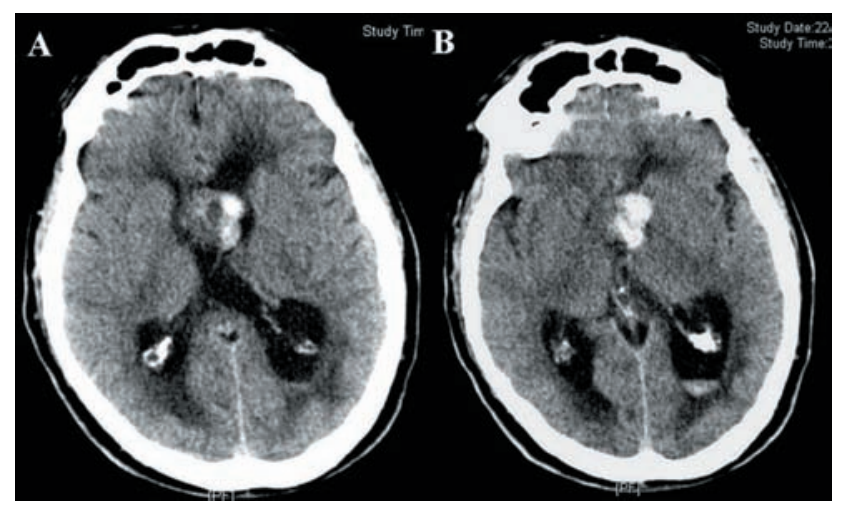

Figure 1. Preoperative CT, showing a $3 \times 2.5 \mathrm{~cm}$ mass located at the left frontal horn, near the foramen of Monro. It causes displacement of the septum pellucidum and obstructive biventricular hydrocephalus, predominantly affecting the left ventricle, with signs of transependymal edema. The lesion is solid, lobulated and shows mild heterogeneous enhancement after contrast administration. It displays a heterogeneous signal with high density areas corresponding to recent intratumoral hemorrhage. A cerebrospinal fluid - blood level can be visualized at the left occipital horn, corresponding to intraventricular hemorrhage (B).

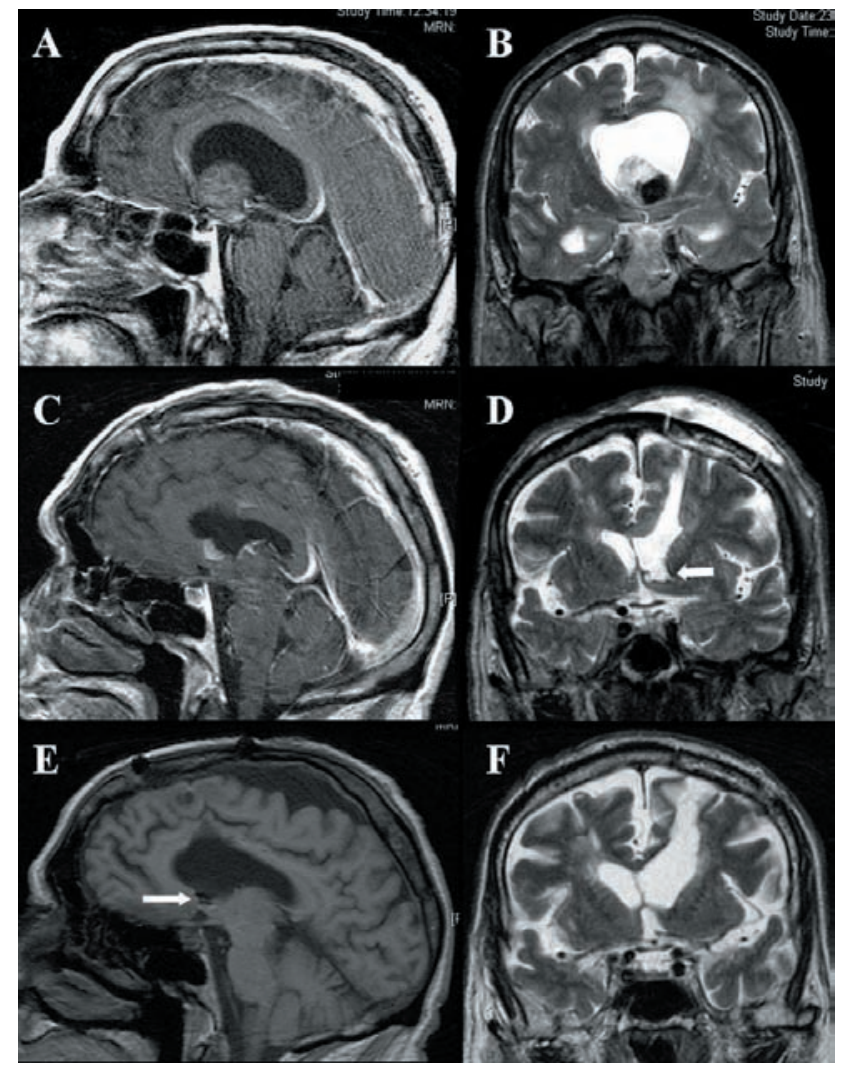

Figure 2. Sequential T1-weighted sagital views (left column) and T2-weighted coronal MRI slices. A) Rounded, sharpdefined tumoral mass located at the left lateral ventricle, displaying an isointense signal and slight heterogeneous Gadolinium enhancement. B) The lesion is hyperintense and presents a hypointense area adjacent to the ventricular floor in this T2-weighted MRI, corresponding to an area of recent hemorrhage. There are signs of obstructive biventricular hydrocephalus and transependymal edema. C-D) Postoperative MRI study performed one week after the surgical procedure. There is no trace of residual tumoral mass, although a small hemorrhagic area becomes evident at the left basal forebrain (white arrow in D). There are no signs of obstructive hydrocephalus. The surgical trajectory and the presence of a postsurgical pseudomeningocele can be easily identified. E-F) There are no signs of tumoral remnants, hemorrhage or pseudomeningocele on this MRI slices obtained after six months of follow-up. There is a small lesion involving the left basal forebrain that coincides with the area of tumoral hemorrhage (white arrow in E).

level of consciousness from drowsiness to coma, requiring orotracheal intubation and mechanical ventilation. He was admitted in the intensive care unit, and an emergent magnetic resonance imaging (MRI) was obtained (fig 2, A-B).

The patient was taken immediately to the operating room. Initial blood test showed an international normalized 


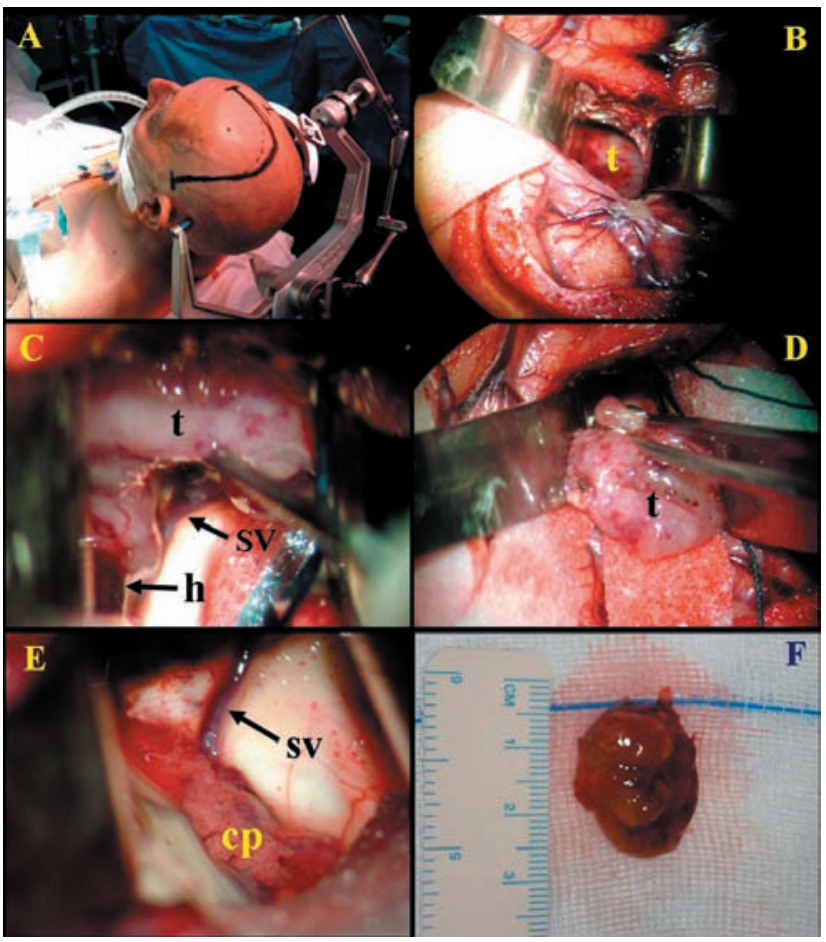

Figure 3.A) The patient was positioned in a neutral position on the Mayfield headholder and a left frontal craniotomy was delineated. B) A trans-sulcal (F1-F2) approach was performed. The tumor ( $t$ ) became evident after disrupting the ependymal wall. C) The gray-pinkish mass showed to be congestive, with hemorrhagic areas. It could be dissected from the septal vein (SV), but it was attached to the ventricular floor by an area of hemorrhage (h). D-F) After complete resection of the tumoral mass, the anatomic elements of the lateral ventricles, such as the septal vein (SV) and the choroid plexus (cp), could be well identified.

ratio value of 3 which was corrected to 1.3 by administering fresh frozen plasma and vitamin $\mathrm{K}$ during the surgical procedure. The tumor was completely removed through a left frontal transcortical approach assisted by neuronavigation (fig 3). An external drainage was left at the lateral ventricle for five days.

After the surgical procedure, the patient recovered progressively his normal level of consciousness. Nevertheless, he presented both temporal and spatial disorientation, and episodes of agitation. In addition, the patient exhibited anterograde and retrograde memory impairment with confabulation. The pathological study was diagnostic for subependymoma displaying areas of hemorrhage (fig 4).

The postoperative MRI study confirmed a complete resection of the mass was achieved (fig 2, C-D). The last follow-up assessment of the patient, performed nine months after the surgical procedure, disclosed an improvement in his memory performance, so he was able to learn
2010; $21: 478-483$

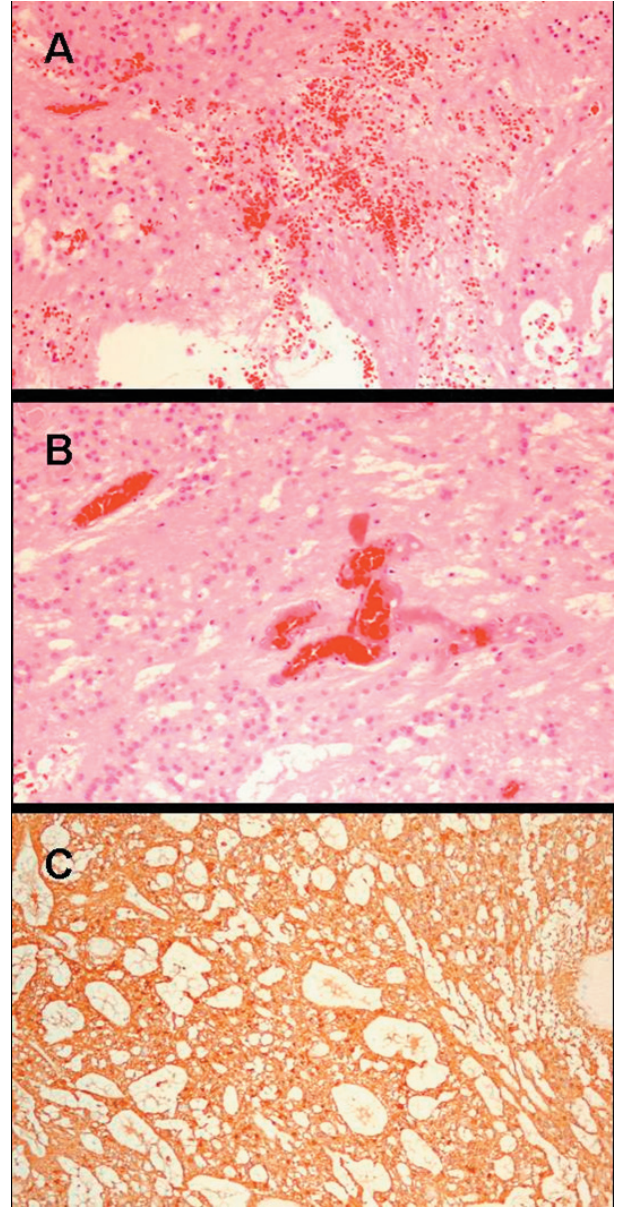

Figure 4. Microscopic study of the tumoral mass. A) Sparse tumoral cells disposed within an eosinophilic fibrillary background (H-Ex 80). There are areas of intratumoral hemorrhage without necrosis. B) Congested capillary vessels can be identified within the tumoral mass (H-E $x$ 150). C) The tumoral cells display an intense positive GFAP immunostaining. Microcystic changes within the fibrillary network can be observed (GFAP x 80).

new material. He also recovered memory for past events, but could not arrange them in sequence. A residual lesion located at the basal forebrain was detected on the MRI, without evidence of hemorrhage or tumoral remnants (fig. 2, E-F).

\section{Discussion}

Subependymomas are benign tumors (WHO grade I) that represent a 0.2 to 0.7 of all intracranial neoplasms. They characteristically affect middle-aged and elderly men, and are preferently located at the fourth ventricle (50$60 \%$ ), followed by the lateral ventricle (30-40\%), septum pellucidum, third ventricle and spinal chord ${ }^{11,13}$. The natural history of subependymomas has not been well defined, but 
Neurocirugía

Hemorrhagic subependymoma of the lateral ventricle

2010; 21478-483

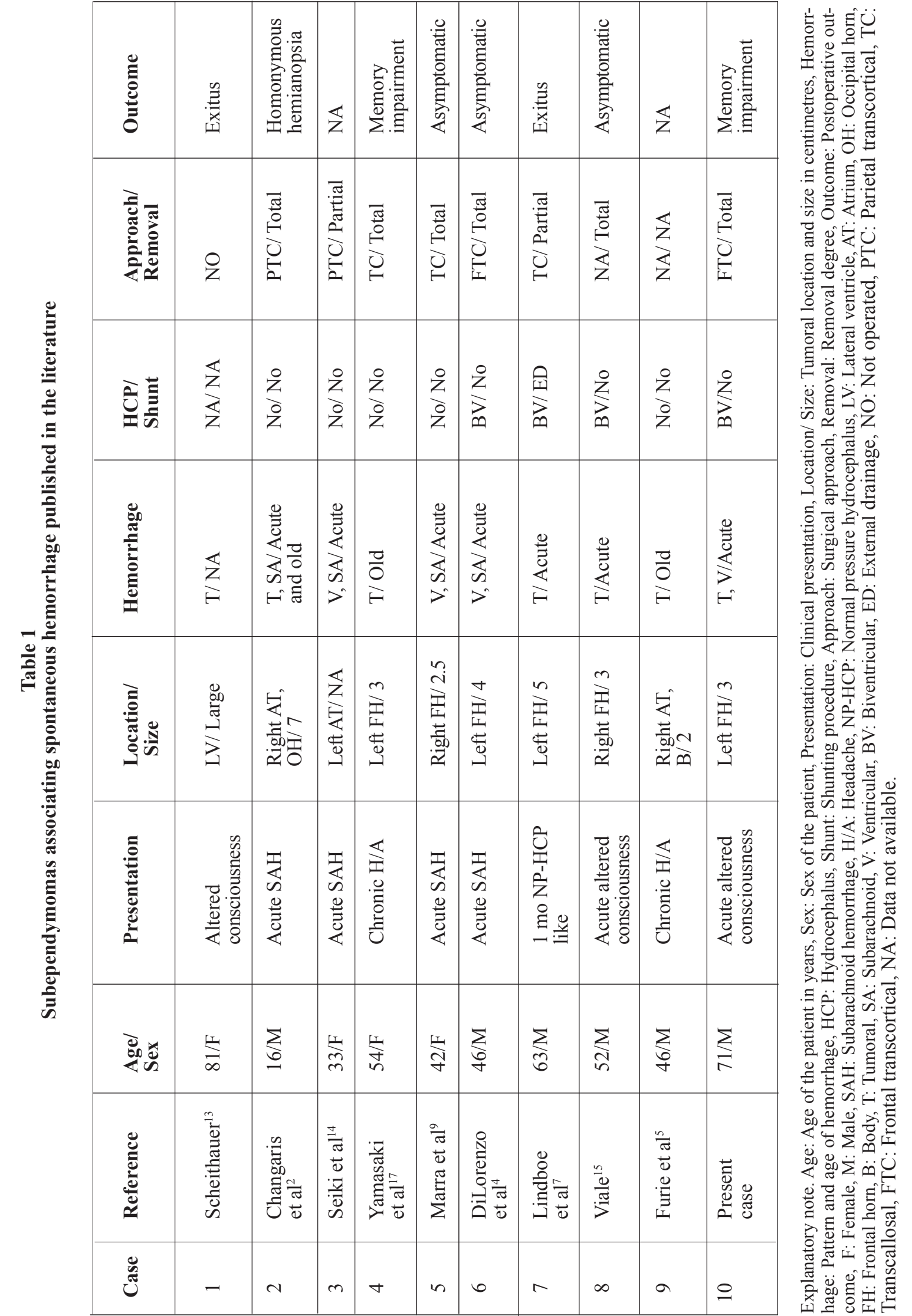


the experience of many cases being found at autopsy and the low frequency of symptomatic cases (37\%) indicates that these tumors display a slow or null rate of growth, with a high probability to remain asymptomatic thorough life $^{9}$. The radiological characteristics of subependymomas are non-specific, making a definite preoperative diagnosis difficult. Aggressive features such as peritumoral vasogenic edema, mass effect, hemorrhage and dense enhancement indicating high vascularity are rare findings $(12 \%)^{11}$.

Overall ten cases of a subependymoma presenting with a hemorrhagic event have been reported in the literature (table 1). Among these cases, three patterns of hemorrhage can be distinguished: pure intratumoral, pure extratumoral (intraventricular and/ or subarachnoid), and finally those subependymomas associating signs of both intra and extratumoral bleeding. The mechanism of spontaneous intratumoral bleeding within a subependymoma remains unclear $^{18}$. Personal antecedents predisposing to hemorrhage have only been described in the case reported by Di Lorenzo (arterial hypertension) and in our own case (anticoagulation $)^{4}$. It is surprising the fact that during the surgical procedure, most authors describe the subependymoma displaying radiological signs of intratumoral bleeding as an avascular mass, being the hemorrhage only demonstrated in the microscopic study. Most of these pathological descriptions include the presence of dilated capillaries, areas of recent microhemorrhages and/ or the presence of hemosiderin-ladden macrophages, indicating old hemorrhage ${ }^{2,17}$. Only in two cases the presence of large areas of massive intratumoral hemorrhage has been reported ${ }^{7,13}$. Noteworthy is the absence of these pathological findings within the cases of subependymoma associating a pure extratumoral hemorrhage, being this phenomenon considered by some authors a consequence of tearing of an ependymal or subependymal vein during tumoral growth ${ }^{14,18}$.

The clinical presentation of hemorrhagic subependymomas depends on the type of bleeding. An acute intratumoral bleeding can produce a sudden increase in the size of the mass, producing acute obstruction of the cerebrospinal fluid pathways, as observed in our patient ${ }^{7,13,15}$. Nevertheless, two cases of subependymomas presenting intratumoral areas of old hemorrhage, who only complained of long-term headache without signs of hydrocephalus, have been described ${ }^{5,17}$. In contrast, the presence of extratumoral hemorrhage can produce a clinical picture indistinguishable from that of a subarachnoid hemorrhage $\mathrm{e}^{2,4,9,14}$. In this context a lumbar puncture may be performed without excluding the presence of a supratentorial mass, with the evident risk of brain herniation.

During the surgical management of a hemorrhagic subependymoma, the neurosurgeon must face two problems, namely hydrocephalus and tumoral removal, almost always being on the diagnostic suspicion of an aggressive

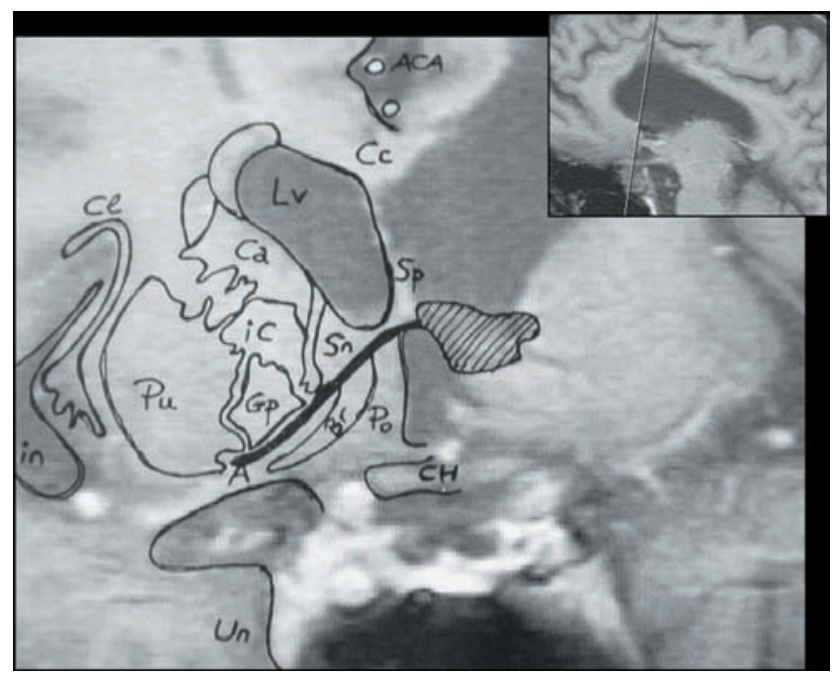

Figure 5. Schematic drawing of the lesion involving the basal forebrain (right side) and anatomical structures affected (left side) over a T1-weighted coronal MRI slice rostral to the anterior comissure. Legends. ACA: Anterior cerebral artery; Cc: Corpus callosum; Lv: Lateral ventricle; Sp: Septum pellucidum; Ca: Head of caudate nucleus; Pu: Putamen; Gp: Globus pallidus; iC: Anterior limb of internal capsule; Sn: Septal nuclei; A: Anterior comissure; Br: Diagonal band of Broca; Po: Preoptic area; CH: Optic chiasm; Cl: Claustrum; in: Insula; Un: Uncus.

neoplasm or a vascular malformation ${ }^{6,11}$. It is our opinion, coincident with the attitude sustained by most authors, that a prompt tumoral removal can solve immediately both problems, avoiding shunting procedures and preventing new hemorrhagic episodes. The surgical approaches to the ventricular system performed by different authors managing hemorrhagic subependymomas were tailored depending on tumoral location and are summarized in table 1. Technical details have been extensively described elsewhere and are out of the scope of this report ${ }^{12}$. Six hemorrhagic subependymomas were completely removed. A partial removal was achieved in two cases, one of them presenting a fatal episode as a consequence of massive rehemorrhage of the residual tumoral mass 7 . One additional fatality was described in a patient who presented with massive intratumoral hemorrhage and could not be operated ${ }^{13}$.

Neurological sequels were detected in three patients after the surgical procedure. Among them, one patient presented a left homonymous hemianopsia as a consequence of a parietal transcortical approach to the ventricular atrium $^{2}$. Yamasaki et al., reported an anterograde memory deficit after a transcallosal removal of a lesion located at the left frontal horn, probably as a consequence of damage to the ipsilateral fornix ${ }^{17}$. Our patient presented disorientation, agitation and a global memory deficit with confabula- 
tion in the acute phase that gradually improved over nine months of follow-up. The discrete residual lesion disclosed on the MRI (fig 2D and 2E) involved the left septal nuclei, the anterior comissure, the diagonal band of Broca, the preoptic area and anterior hypothalamus (fig 5).

This kind of basal forebrain lesion, mainly seen after removal of tumors and hemorrhage from anterior communicating aneurysms, tends to produce memory deficits which are less severe than those observed in patients with medial diencephalic or mesial temporal lobe damage, and characteristically do not affect non - declarative memory ${ }^{10,16}$. It has been postulated that the amnesia following basal forebrain damage can be a consequence of the interruption of the cholinergic innervation that the nuclei located in this anatomical region provide to the hippocampus and neocortical areas ${ }^{1,3,10,16}$. Nevertheless, the presence of clinically evident memory dysfunctions seems to depend on a combination of basal forebrain nuclei and fiber tracts lesions rather than on damage to a single structure ${ }^{16}$.

\section{References}

1. Abe, K., Inokawa, M., Kashiwagi, A., Yanagihara, T.: Amnesia after a discrete basal forebrain lesion. J Neurol Neurosurg Psychiatry 1998; 65: 126-130.

2. Changaris, D.G., Powers, J.M., Perot, P.L. Jr, Hungerford, G.D., Neal, G.B.: Subependymoma presenting as subarachnoid hemorrhage: case report. J Neurosurg 1981; 55: 643-645.

3. Damasio, A.R., Graff-Radford, N.R., Eslinger, P.J., Damasio, H., Kassell, N.: Amnesia following basal forebrain lesions. Arch Neurol 1985; 42: 263-271.

4. DiLorenzo, N., Rizzo, A., Ciappetta, P.: Subependymoma of the septum pellucidum presenting as subarachnoid hemorrhage. Neurochirurgia (Stuttg) 1991; 34: 125-126.

5. Furie, D.M., Provenzale, J.M.: Supratentorial ependymomas and subependymomas: CT and MRI appearance. J Comput Assist Tomogr 1995; 19: 518-526.

6. Koeller, K.K., Sandberg, G.D.: From the archives of the AFIP. Cerebral intraventricular neoplasms: radiologic-pathologic correlation. Radiographics 2002; 22: 1473-1505.

7. Lindboe, C.F., Stolt-Nielsen, A., Dale, L.: Hemorrhage in a highly vascularized subependymoma of the septum pellucidum: Case report. Neurosurgery 1992; 31: 741-745.

8. Maiuri, F., Gangemi, M., Iaconetta, G., Signorelli, F.,
Del Basso De Caro, M.: Symptomatic subependymomas of the lateral ventricles. Report of eight cases. Clin Neurol Neurosurg 1997; 99: 17-22.

9. Marra, A., Dario, A., Scamoni, C., Cerati, M., Crivelli, G., Dorizzi, A.: Intraventricular subependymoma presenting as subarachnoid hemorrhage. Case report. J Neurosurg Sci 1991; 35: 213-215.

10. Morris, M.K., Bowers, D., Chatterjee, A., Heilman, K.M.: Amnesia following a discrete basal forebrain lesion. Brain 1992; 115: 1827-1847.

11. Ragel, B.T., Osborn, A.G., Whang, K., Townsend, J.J., Jensen, R.L., Couldwell, W.T.: Subependymomas: An analysis of clinical and imaging features. Neurosurgery 2006; 58 : 881890.

12. Rothon, A.L.J.: The lateral and third ventricles. Neurosurgery 2002; 51(Suppl 1): 207-271.

13. Scheithauer, B.W.: Symptomatic subependymoma: Report of 21 cases with review of the literature. J Neurosurg 1978; 49: 689-696.

14. Seiki, Y., Terao, H., Shibata, I., Tsukahara, K., Tsutsumi, S., Kudo, M.: A case of subependymoma in the lateral ventricle with intraventricular hemorrhage. No Shinkei Geka 1984; 12: 761-765.

15. Viale, G.L.: Subependymomas of the lateral ventricles. Br J Neurosurg 1994; 8: 765-767.

16. von Cramon, D.Y., Müller, U.: The septal region and memory. Adv Tech Stand Neurosurg 1998; 24: 3-40.

17. Yamasaki, T., Kikuchi, H., Higashi, T., Yamabe, H., Moritake, K.: Two surgically cured cases of subependymoma with emphasis on magnetic resonance imaging. Surg Neurol 1990; 33: 329-335.

18. Yuguang, L., Meng, L., Shugan, Z., Yuquan, J., Gang, L., Xingang, L., Chengyuan, W.: Intracranial tumoural haemorrhage-a report of 58 cases. J Clin Neurosci 2002; 9: 637-639.

Carrasco, R.; Pascual, J.M.; Navas, M.; Fraga, J.; Manzanares-Soler, R.; Sola, R.G.: Spontaneous acute hemorrhage within a subependymoma of the lateral ventricle: successful emergent surgical removal through a frontal transcortical approach. Neurocirugía 2010; 21: 478-483.

Corresponding author: Rodrigo Carrasco, MD. Department of Neurosurgery. Ramón y Cajal University Hospital. Carretera de Colmenar Viejo, Km 9,100. 28049, Madrid, Spain.

e-mail: rocamo@gmail.com 